\title{
Vaso-occlusive crisis in sickle cell disease: a vicious cycle of secondary events
}

\author{
Tim Jang, Maria Poplawska, Emanuela Cimpeanu, George Mo, Dibyendu Dutta and Seah H. Lim (1)
}

\begin{abstract}
Painful vaso-occlusive crisis (VOC) remains the most common reason for presenting to the Emergency Department and hospitalization in patients with sickle cell disease (SCD). Although two new agents have been approved by the Food and Drug Administration for treating SCD, they both target to reduce the frequency of VOC. Results from studies investigating various approaches to treat and shorten VOC have so far been generally disappointing. In this paper, we will summarize the complex pathophysiology and downstream events of VOC and discuss the likely reasons for the disappointing results using monotherapy. We will put forward the rationale for exploring some of the currently available agents to either protect erythrocytes un-involved in the hemoglobin polymerization process from sickling induced by the secondary events, or a multipronged combination approach that targets the complex downstream pathways of VOC.
\end{abstract}

Keywords: Sickle cell disease, Secondary vaso-occlusive crisis, Downstream events, Treatment strategies

\section{Background}

Sickle cell disease $(\mathrm{SCD})$ is a genetic disorder of the hemoglobin $(\mathrm{Hb})$ affecting $\sim 30$ million people worldwide [1]. It is characterized by a point mutation that results in the substitution of glutamic acid with valine on the sixth amino acid of $\beta$-globin. The mutant Hb molecules, hemoglobin $\mathrm{S}(\mathrm{HbS})$, polymerize upon deoxygenations, causing the erythrocytes to assume a sickle morphology and reduce the fluidity of the cell membrane. Sickle erythrocytes adhere to leukocytes immobilized to the endothelium, causing microvascular occlusion, vaso-occlusive crisis (VOC), and tissue ischemia. Recurrent vaso-occlusion causes chronic disabling arthritis due to osteonecrosis affecting the joints, progressive retinopathy, chronic renal failure, increased risks for strokes, and shortened lifespan.

In the United States, although only 100,000 Americans are affected by the disease [1], they impose high

*Correspondence: seahhlim1@gmail.com

Division of Hematology and Oncology, Department of Medicine, SUNY Downstate Medical Center, SUNY Downstate Health Sciences University, 450 Clarkson Avenue, MSC \#20, Brooklyn, NY 11203, USA healthcare utilization [2]. In 2004, more than 80,000 hospitalizations were incurred by adult SCD patients in the US, costing nearly $\$ 500$ million, with majority of the cost arising from inpatient hospitalization associated with VOC [3]. A benchmark study found a mean annual rate of 1.52 admissions per SCD patients [3]. Efforts in the Emergency Department (ED) to reduce the number of hospitalizations has met with limited successes. A study involving nearly 40,000 ED visits for VOC found that more than $40 \%$ of the treat-and-release visits had either an inpatient hospitalization or another ED treat-andrelease visit within 14 days of the index ED visit [4].

VOC has previously been suggested to consist of four phases [5, 6]. Phase 1 spans $\sim 3$ days and is associated with a low-intensity aching pain. The patient may also report numbness and paresthesia. The aching increases rapidly in Phase 2, to maximum pain due to local tissue infarct from vaso-occlusion. Phase 3 of VOC is due to post-infarct inflammatory responses and is when the severe pain becomes constant and this may be associated with a fever. Phase 3 usually lasts three to five days. This is followed by the resolution of the VOC in Phase 4 over one to two days. Although the phasic process of VOC original author(s) and the source, provide a link to the Creative Commons licence, and indicate if changes were made. The images or other third party material in this article are included in the article's Creative Commons licence, unless indicated otherwise in a credit line to the material. If material is not included in the article's Creative Commons licence and your intended use is not permitted by statutory regulation or exceeds the permitted use, you will need to obtain permission directly from the copyright holder. To view a copy of this licence, visit http://creativecommons.org/licenses/by/4.0/. The Creative Commons Public Domain Dedication waiver (http://creativecommons.org/publicdomain/zero/1.0/) applies to the data made available in this article, unless otherwise stated in a credit line to the data. 
appears straightforward, various clinical observations suggest that VOC is in fact a fluid process that does not always follow this sequence of events. Phases $2 / 3$ are not always followed by Phase 4 . Instead, these phases may feedback into Phase 1 to create a vicious cycle of VOC that we previously proposed [7]. Examples supporting this notion are seen in the prolonged hospital length-ofstay (LOS) beyond the average of five days for an episode of VOC [8] in many patients, the development of worsening symptoms, and the onset of acute chest syndrome during hospital stay. We recently found in a study in our institution of more than 100 episodes of uncomplicated VOC admissions that $3 \%$ of these patients subsequently developed acute chest syndrome during hospitalization [9]. In patients treat-and-released in ED for painful crisis, there was also a high frequency of subsequent inpatient hospitalization or another ED visit within 2 weeks [4]. Given the complexity of VOC and its positive feedback mechanism that may further exacerbate the pain crisis and to set up a vicious cycle that we now term secondary $\mathrm{VOC}(\mathrm{sVOC})$, adequate and aggressive intervention of VOC at the earliest time is crucial. This will break the vicious cycle and shorten hospital LOS due to pain, although the component of pain due to tissue infarct may not be rescuable. Here, we defined sVOC as VOC that arises from the downstream processes caused by the initial VOC episodes. In this paper, we will summarize the mechanisms and pathophysiology of the chronic inflammatory processes associated with $\mathrm{SCD}$, define and examine the molecular events of $\mathrm{VOC}$ and how they might promote $\mathrm{SVOC}$, and propose a multipronged approach for the management of $\mathrm{VOC}$ episodes to prevent the development of sVOC.

\section{Chronic inflammatory processes in sickle cell disease}

In addition to erythrocyte sickling, one of the hallmarks of SCD is the continuous presence of basal inflammatory processes. This is exemplified in the following observations. SCD patients have higher baseline leukocyte counts than those without the disease [10]. Although the elevated leukocytes may be contributed by the overstimulated marrow from the underlying hemolytic process, SCD patients exhibit higher levels of soluble CD62L $[11,12]$, a marker of neutrophil activation. Neutrophils in SCD also express higher activation molecules, e.g. CD64 [12] and CD11b/CD18 [13]. Monocytes in SCD demonstrate activated phenotypes and higher propensity to IL-1 $\beta$ and TNF $\alpha$ [14]. Similarly, platelets in SCD are chronically activated and express higher level of CD40L [15]. The ongoing inflammatory processes provide the background on which VOC develops. The ongoing inflammatory processes originate from a combination of membrane damage of erythrocytes carrying $\mathrm{HbS}$ and increased intestinal permeability that occurs in SCD (Fig. 1). However, once VOC is triggered, ischemia-reperfusion injury that follows further feeds into the inflammatory processes.

\section{Endogenous stimuli promoting inflammatory processes in sickle cell disease}

$\mathrm{HbS}$ causes damage to erythrocyte membrane. In addition to background polymerization that affects the fluidity of the membrane, $\mathrm{HbS}$ precipitates on the inner surface of the membrane following auto-oxidation and generates iron-dependent free radicals that impact membrane damage [16]. The damaged membrane renders the erythrocytes more adherent to the endothelium although works involving intravital microscopy found that sickle erythrocytes are more prone to adhere to leukocytes immobilized on endothelium than directly to endothelial cells [17].

Before the development of $\mathrm{VOC}$ and the consequences of ischemia-reperfusion injury, the hemolysis of erythrocytes in SCD per se promote inflammation. As a result of intravascular hemolysis, free heme is released by the damaged erythrocytes. Free heme activates complements [18]. It mediates pro-inflammatory processes by modulating macrophages via transcription factors such as $\mathrm{BTB}$ and $\mathrm{CNC}$ homologue (BACH) 1 and Spi-C [19]. Free heme also promotes neutrophil extracellular traps (NETosis) [20]. These ongoing inflammatory processes are, however, kept in equilibrium by various adaptive regulatory mechanisms that include nitric oxide and macrophages. In addition, extracellular heme released from hemolysis bind to plasma heme scavenger proteins such as haptoglobin and undergo further degradation in the liver [21]. These regulatory mechanisms, therefore, keep the processes in a newly established homeostasis and prevent the development of VOC.

\section{Exogenous stimuli promoting inflammatory processes in sickle cell disease}

In addition to the endogenous stimuli, exogenous stimuli in the form of lipopolysaccharides (LPS) also promote the inflammatory processes in SCD. SCD patients exhibit higher level of serum LPS compared to non-SCD patients [11]. LPS not only stimulates and activate neutrophils [22] and monocytes [23], it also regulates aging of neutrophils via its interaction with Myd88 and TLR2/4 [24]. The elevated levels of serum LPS are likely related to increased translocation of bacteria/bacterial products across the intestinal barrier caused by enterocyte injury. The higher levels of serum intestinal fatty acid binding protein (iFABP) detected in the serum of SCD patients would support this notion [11]. Whether the enterocyte injury results in straightforward anatomical defects of 


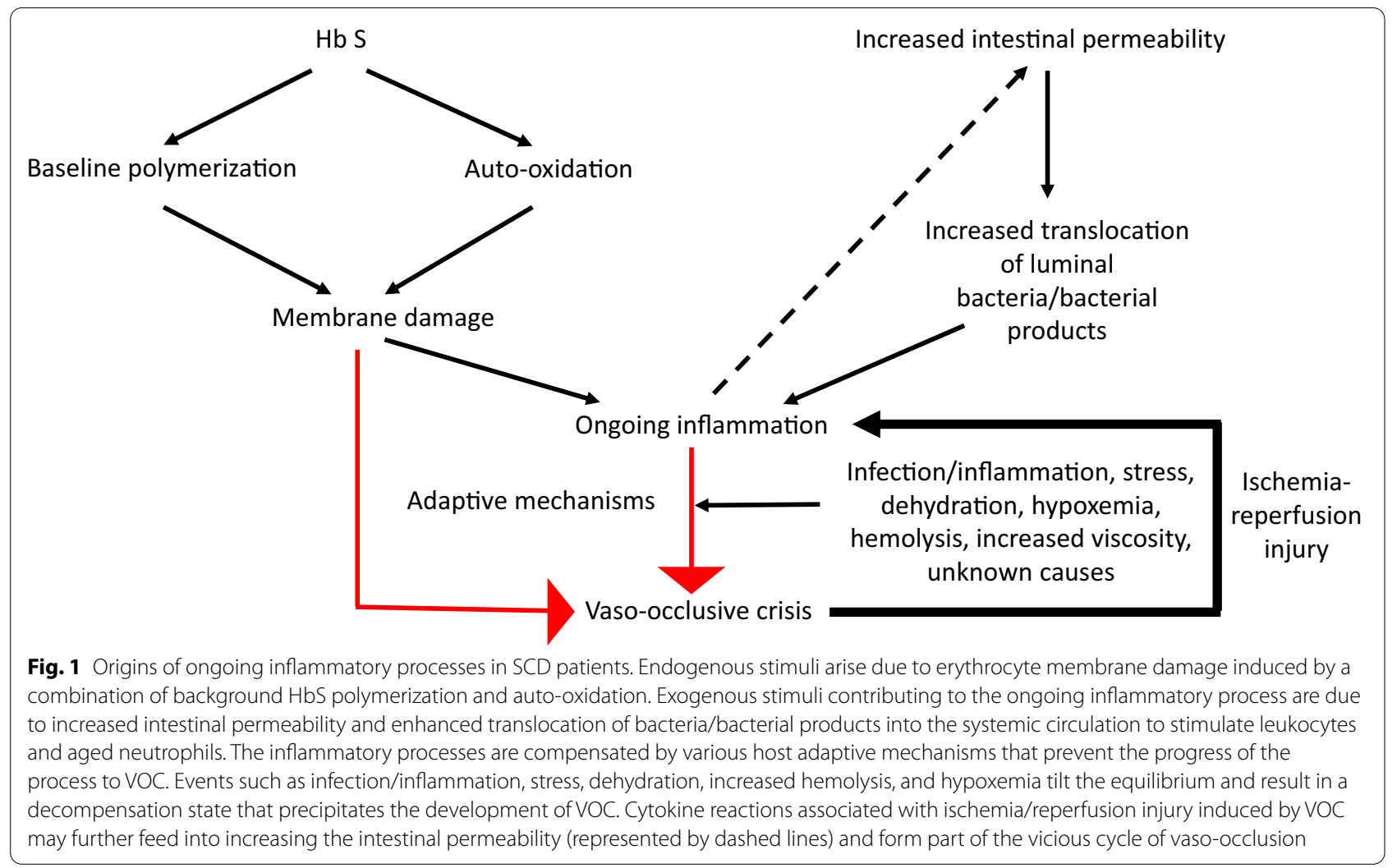

the intestinal barrier and/or downregulation of the tight junctions between enterocytes remains to be established. The latter may be supported by the ability of L-glutamine to reduce the frequency of VOC in SCD [25]. It is likely the intestinal microbial load and composition also play a role. SCD patients show intestinal dysbiosis [26]. Antibiotic administration to SCD patients [27] and mice [24] both led to drops in circulating aged neutrophils (CANs), through a combination of reduction in the intestinal microbial load and alteration in the microbial compositions [28]. In SCD patients, there were also associated drops in the serum CD62L [28], indicating a downregulation of the inflammatory processes when the intestinal microbial load and/or composition is altered.

\section{Ischemia-reperfusion injury}

The ongoing inflammatory processes are further worsened if VOC occurs because VOC is invariably followed by ischemia-reperfusion injury. Ischemia-reperfusion injury promotes inflammation by the production of oxygen species that damages local tissues [29]. The damaged tissue increases adhesion and activation of leukocytes, with consequences of cytokine secretion and release of tissue factor that activate the coagulation pathway to promote local thrombotic events [30] that will worsen hypoxemia and provide a positive-feedback to the inflammatory cascade. Ischemia-reperfusion injury also activates invariant Natural killer T (iNKT) cells via CD1d. iNKT cells are hyper-responsive to changes due to reperfusion and secretes chemokines to recruit more leukocytes to the local area of inflammation and worsen tissue damage [31].

\section{Consequences of chronic inflammatory processes in sickle cell disease}

The extent of the balance between chronic inflammatory processes and various adaptive mechanisms that maintain the equilibrium probably varies among different SCD individuals. Susceptibility to developing VOC among different individuals may depend on the size of the adaptive reserves in the compensated state. This will be discussed further in the next section.

Ongoing inflammatory processes not only render SCD patients to developing VOC, they also create a prothrombotic state [32]. In addition, ongoing inflammations create a state of hypermetabolism that may be responsible for the lower appetite and consequent calorie intake [33] and low prevalence of obesity and diabetes mellitus [34] among SCD patients. 
Pathogenesis and molecular events of vaso-occlusive crisis The mechanism of VOC is complex and yet to be fully dissected. However, it is most likely VOC occurs when the balance between the pathologic processes of SCD responsible for the ongoing inflammation and the hosts adaptive mechanisms is disrupted in favor of the pathologic processes. As a result, the host adaptive mechanisms are overwhelmed, and this leads to decompensation of the balanced state.

VOC begins with increased sickling and interaction of the sickle erythrocytes with the endothelium in the postcapillary venules, either directly or by way of leukocytes adherent to the endothelium, leading to obstruction of blood flow that triggers a host of signaling cascades. Leukocytes that adhere to the endothelium and form the nidus for sickle erythrocytes to be attached to include activated leukocytes and aged neutrophils. Following the development of vaso-occlusion, several downstream pathologic processes are amplified beyond those that can be held in check by the host adaptive mechanisms. Although the mechanisms are yet to be fully understood, VOC creates a number of distinct downstream processes that are important contributors to the vicious cycle of the complication (Fig. 2).

\section{Increased release of free heme}

When VOC occurs following a precipitating event, the hemolytic process of sickle erythrocytes is increased, with subsequent release of more free heme. Normally, extracellular heme binds to various plasma heme scavenger proteins such as haptoglobin and undergo degradation in the liver [21]. However, due to chronic hemolysis, heme-binding proteins are chronically low in most SCD patients. As a result, free heme accumulates in the system [35]. Elevated levels of free heme are associated with increased incidence of VOC [36]. Free heme stimulates the migration of leukocytes to the endothelial wall where they bind to P- and E-selectins and promote the production of reactive oxygen species (ROS) [37]. Leukocytes immobilized to the endothelium form the nidus for the adherence of sickle erythrocytes, leading to vascular obstruction and local hypoxemia. Vaso-occlusion is also made worse when the activated neutrophils interact with each other to create a network of obstructive strands that consist of neutrophil DNA, histones, proteases, and nucleosomes that are expelled from the decondensed chromatins in the nucleus, a process known as NETosis [38]. Although NETosis is an important host defense system against microorganisms, it incurs injury to the

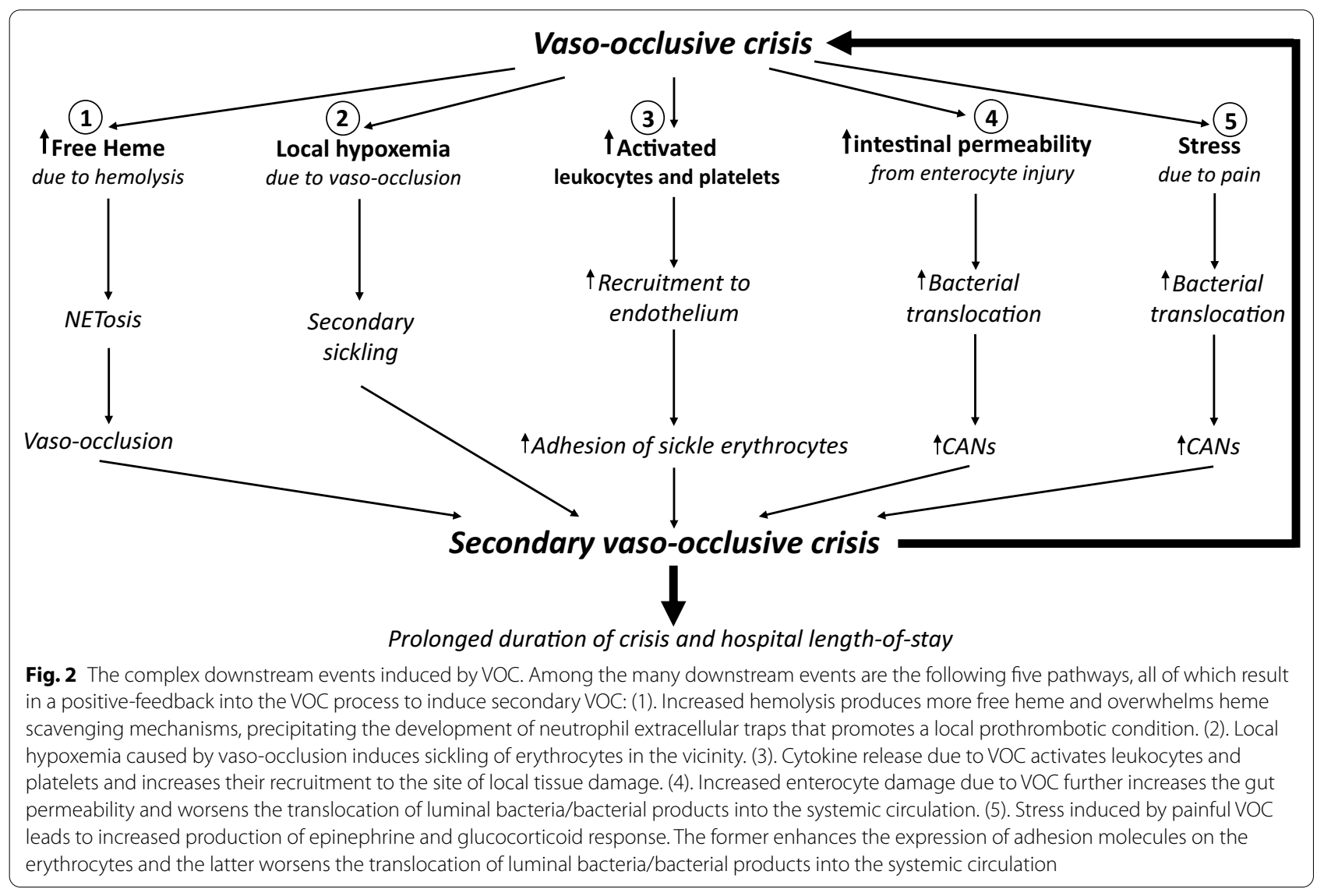


endothelial cells as well as parenchymal tissues across organs [39]. It also stimulates the coagulation cascade $[40,41]$. Free heme-mediated pathologic processes create additionally a local microenvironment favoring further sickling of the erythrocytes and the development of sVOC.

\section{Secondary sickling induced by local hypoxemia and activation of leukocytes and platelets}

As a result of VOC, hypoxemia in the vicinity of the vaso-occlusion occurs. Hypoxemia provides the positive feedback to induce polymerization of $\mathrm{HbS}$ in erythrocytes that have not previously been involved in the sickling process. Hypoxemia also activates monocytes [42] and platelets [43], and enhances neutrophil inflammatory responses [44]. Both processes facilitate the recruitment and adherence of these activated blood cells to the endothelium to provide the niduses for sickle erythrocytes to be attached to, setting up a vicious cycle of sVOC.

\section{Increased intestinal permeability}

As discussed in the earlier section, SCD patients exhibit increased intestinal permeability [11] that facilitates enhanced translocation of bacteria/bacterial products across the intestinal barrier into the systemic circulation. Increased bacteria/bacterial products in the systemic circulation activates neutrophils and contributes to the ongoing inflammatory processes. In addition, it may also upregulate the expansion of CANs [24]. Unpublished data from our laboratory in experiments using gastric gavage administration of FITC-dextran $4 \mathrm{k}$ to Townes SCD mice found that the intestinal barrier is acutely breached in response to VOC. The increased intestinal permeability is most likely related to enterocyte injury [11], although the pathologic mechanisms responsible for the enterocyte injury remain to be determined. Possible causes include hypoxemic and ischemia-reperfusion injuries from VOC affecting the splanchnic vasculature, direct effects of the inflammatory cytokines on the enterocytes, and intestinal dysbiosis [26]. Both activated and aged neutrophils are highly adherent to endothelial cells and they fuel sVOC.

\section{Increased stress-induced responses}

VOC may induce intense sympathetic responses from stress due to pain. The sympathetic responses result in the release of epinephrine and glucocorticoids. Epinephrine upregulates the expression of intercellular adhesion molecule-4 (ICAM-4) on erythrocytes [45], promoting their binding to endothelial $\alpha v \beta 3$ to worsen the VOC. This may explain the pathogenesis of stress being a precipitating factor of VOC [46]. A recent study in mice found that stress-induced VOC is facilitated through intestinal microbiota [47]. Stress leads to augmented glucocorticoid ressponse and subsequent higher gut permeability, which promotes microbiota-dependent interleukin-17A (IL-17A) secretion and increase in circulating pool of CANs. Intestinal microbiota-mediated CAN expansion is mediated particularly by Gram-positive organisms. Stress, therefore, could potentially feed into the vicious cycle of VOC by promoting the development of sVOC.

\section{Therapeutic agents that may modify acute vaso-occlusive crisis}

The FDA has approved L-glutamine and crizanlizumab for SCD to reduce the frequency of VOC, they are not for treating VOC in the acute setting to prevent the development of sVOC. To be beneficial in treating VOC, an agent has to be able to mediate its effects promptly after administration to interrupt the vicious cycle of VOC to prevent sVOC. Clinical trials investigating specific agents for treating VOC have focused on targeting the downstream events and have uniformly been disappointing. This is not surprising taking into consideration that VOC is a complex pathologic process and leads to many downstream events. Currently, the mainstay of management in SCD patients with acute VOC is intravenous hydration and opioid analgesia. This conservative approach aims to treat the patients symptomatically and wait for the VOC process to resolve spontaneously. In this section, we will discuss some of the therapeutic agents that may be investigated for use during acute VOC to either protect erythrocytes that are not already involved in the hemoglobin polymerization process from undergoing sickling, or downregulate the downstream effects of VOC.

\section{Anti-sickling agents}

Even during an acute VOC episode, only a population of $\mathrm{HbS}$ erythrocytes are affected by the sickling process. It, therefore, follows that protecting or "fortifying" the uninvolved $\mathrm{HbS}$ erythrocytes from sickling and subsequent sVOC is a rational and probably most effective approach since this would provide protection without having to address the multi-pathway secondary events. HbS erythrocytes can be prevented from sickling by increasing the oxygen affinity of SCD erythrocytes. Although increasing the fetal hemoglobin that has a high affinity for oxygen using hydroxyurea [48], DNA hypomethylating agents [49], or phosphodiesterase 9 inhibitors [50] prevents sickling, such approaches are not relevant in the acute setting to prevent sVOC. However, other strategies might be explored. Increasing the oxygen affinity of $\mathrm{HbS}$ using the allosteric modifier, voxelotor [51], is a very attractive option since voxelotor binds directly to $\mathrm{HbS}$ to modify 
its oxygen affinity rapidly. Pharmacokinetic studies support the feasibility of this approach since the maximum concentration in plasma is reached within two hours and whole blood in six hours [52] following an oral dose of voxelotor. It should, however, be pointed out that voxelotor did not manage to reduce the frequency of $\mathrm{VOC}$ in a randomized study [51].

$\mathrm{N}$-acetylcysteine (NAC) reduces erythrocyte oxidative stress [53] and prevents sickling of HbS erythrocytes. Although a Phase 3 placebo-controlled randomized study failed to support its use to reduce the frequency of VOC [54], its role in treating VOC and preventing sVOC has not been examined. Pharmacokinetic studies of NAC would support its potential role in the acute setting. Its maximum concentration in plasma can be reached between half and three hours after one single oral dose [55]. NAC is currently not licensed for use in SCD.

Other approaches that may improve the oxygen affinity of $\mathrm{HbS}$ erythrocytes in the acute setting that are currently being investigated include the use of pyruvate kinase activators $[56,57]$. These agents stimulate the glycolytic pathway to deplete the intra-erythrocyte 2,3-diphosphoglycerate.

\section{Anti-inflammatory agents}

Since intense inflammatory processes are associated with VOC, the use of anti-inflammatory agents may be appropriate. Although it is the gold standard for treating SCD, less than $30 \%$ of SCD patients are on long-term hydroxyurea [58]. Therefore, a high proportion of SCD patients admitted to the hospital are not already on the medication. Its use during active VOC will not result in induction of HbF. However, hydroxyurea mediates antiinflammatory processes associated with SCD [59, 60], probably via downregulation of STAT3 and may prevent the development of sVOC. Furthermore, the rapid onset of myelosuppression, usually within 36-48 h, when used in high doses may also provide benefits to reduce the pool of activated and aged neutrophils that participate in VOC and sVOC. The use of high dose urea during acute VOC is being investigated (Clinicaltrial.gov: NCT03062501).

Anti-inflammatory agents may prevent the development of sVOC. Although NSAID such as ketorolac has been incorporated in the pain management of SCD [61], there has not been any studies demonstrating their use in preventing sVOC and shortening the duration of the crisis. They should also be used with caution in view of the high frequency of renal impairment in this group of patients. On the other hand, high dose intravenous methylprednisolone to shortened the duration of hospital stay compared to those on the placebo arm, although the patients were more likely to be readmitted to the hospital after discharge due to rebound toxicity [62]. These results support the role of corticosteroids in the treatment of VOC but how they should be used to reduce the likelihood of hospital readmissions remains to be established.

\section{Agents targeting adhesion}

Adherence of sickle erythrocytes to the endothelium occurs either directly, or more often, via activated leukocytes adherent to the endothelium. Targeting cellular adhesion molecules involved in their interaction, once VOC occurs, will reduce the likelihood of development of sVOC. Crizanlizumab, a monoclonal antibody against P-selectin [63] and has been approved by the FDA for use to reduce the frequency of VOC, may be a suitable agent to treat VOC to prevent sVOC. On the other hand, rivipansel, a pan-selectin antibody, has been shown in a Phase 2 study to shorten the duration of VOC compared to placebo [64], although the results (yet to be published) from its Phase 3 study failed to meet both its primary and secondary endpoints. Investigations on the role of antibodies directed at iNKT cells activated by ischemiareperfusion injury to treat $\mathrm{VOC}$, unfortunately, failed to show benefits [65].

Based on the laboratory results showing the ability of IVIg to reverse acute VOC in SCD mice [66, 67], a Phase $1 / 2$ study was performed with a fixed dose of IVIg at $800 \mathrm{mg} / \mathrm{kg}$. Unfortunately, the laboratory successes could not be reproduced in the clinic [68]. It may be worthwhile exploring a higher dose of IVIg, although it will have to be administered carefully due to the high sodium load on the renal functions.

\section{Modulators of intestinal pathology}

As discussed above, SCD is associated with intestinal pathology that contributes to the chronic inflammatory processes and the development of VOC. Targeting the intestinal pathology during $\mathrm{VOC}$ may, therefore, reduce the likelihood for the development of sVOC. Intestinal barrier in SCD may be improved by L-glutamine that enhances enterocyte health and the development of tight junctions [69]. L-glutamine is approved by the FDA for treating SCD based on a randomized study showing reduction in the frequency of $\mathrm{VOC}$ in those treated with L-glutamine, compared to placebo [25], although the mechanisms responsible for the clinical benefits remain to be determined. L-glutamine use during VOC episodes may restore intestinal barrier and reduce the bacteria/ bacterial product translocation.

Based on a small study showing that the antibiotic rifaximin reduced the frequency of $\mathrm{VOC}$, rifaximin [27] may also be tried during VOC episodes to reduce the intestinal microbial load and prevent sVOC. Rifaximin use in the preventive setting reduce the number of CANs and serum LPS [28]. Antibiotic use may also 
downregulate the VOC due to microbiota-mediated expansion of CANs [47] induced by the stress due with pain during VOC.

\section{Modulators of VOC pathway induced by stress}

VOC is associated with intense sympathetic responses due to pain. As discussed above, epinephrine upregulates the expression of adhesion molecules on erythrocytes [45] to promote VOC. In addition, the augmented glucocorticoid responses increase gut permeability and promotes microbiota-dependent IL-17A secretion [47], leading to the precipitation of VOC. Downregulation of the sympathetic responses may interrupt the vicious cycle of VOC. This may be accomplished with the use of $\beta$-blocker such as propranolol [70], or more appropriately, with aggressive analgesia treatment. Early achievement of maximum analgesia improved hospitalization outcomes [71].

\section{Nitric oxide facilitators}

One of the hallmarks of SCD, especially during VOC episodes, is the depletion of nitric oxide (NO). NO mediates vaso-dilatation. $\mathrm{NO}$ depletion causes vaso-constriction and increases the risks for VOC. Enhancing NO availability during $\mathrm{VOC}$ is, therefore, rational and may prevent sVOC. $\mathrm{NO}$ availability can be derived from inhaled NO during VOC or use of agents such as L-citrulline [72] and L-arginine [73], both are substrates in the NO cycle. Clinical studies using inhaled NO monotherapy to treat VOC, however, did not find any obvious clinical benefits $[74,75]$.

\section{Modulators of blood viscosity}

The rationale for the administration of intravenous fluid to SCD patients during VOC episode is to treat any underlying dehydration that could have precipitated the VOC, reduce the blood viscosity to prevent the development of sVOC, and perhaps, dilute the inflammatory cytokines associated with VOC. Unless contraindicated or with a history of fluid overload that occurs not infrequently in SCD patients [76], these patients should receive aggressive intravenous fluid with hypotonic and low sodium fluid to reduce the sodium intake since SCD patients have reduced ability to excrete sodium load [77].

As a result of NETosis, the DNA strands increases blood viscosity and stimulate the coagulation cascade
[41] that would feed into the vicious cycle of VOC to induce sVOC. Administration of DNAse to SCD mice has produced beneficial effects of VOC [20]. Such an approach might be investigated in future in human using recombinant human DNAse.

\section{Antiplatelets and anticoagulation therapy}

VOC activates platelets and the coagulation cascade. Use of antiplatelet and anticoagulating agents during acute VOC episodes is, therefore, rational. Unfortunately, their use individually as monotherapy for treating VOC has so far not produced significant benefits [78-81].

\section{Conclusions}

While advances have been made to reduce the frequency of VOC in SCD, there have been very little change in the management of patients during episodes of VOC. The current passive approach relies solely on supportive measures and wait for the spontaneous resolution of the VOC episodes. As a result, the duration of VOC is prolonged in patients who are caught in the vicious cycle of the pathology with the development of sVOC. A more aggressive approach that would treat the VOC instead is needed. The results from various studies on treating VOC using monotherapy have so far been universally disappointing. This is not surprising in view of the complex nature of VOC. Unless targeting the erythrocytes to protect the un-involved $\mathrm{HbS}$ erythrocytes from secondary sickling, successful treatment of VOC targeting of the downstream pathways requires multipronged approaches using combination therapy, just like treatment of malignant diseases using combination chemotherapy. Based on these arguments, it is possible that treatment of acute VOC to prevent sVOC may only be efficacious using monotherapy with agents that increase the oxygen affinity acutely to prevent further sickling, or combination therapy that targets multiple downstream processes. Figure 3 represents a multimodality approach based on the agents currently available in the market that could be investigated in various combinations that cover as many of the different downstream events as possible to prevent the development of sVOC. The combination of approaches targeting more than one downstream pathway may shorten the duration of VOC and reduce the hospital LOS so that the patient can be discharged and managed on oral analgesia. 


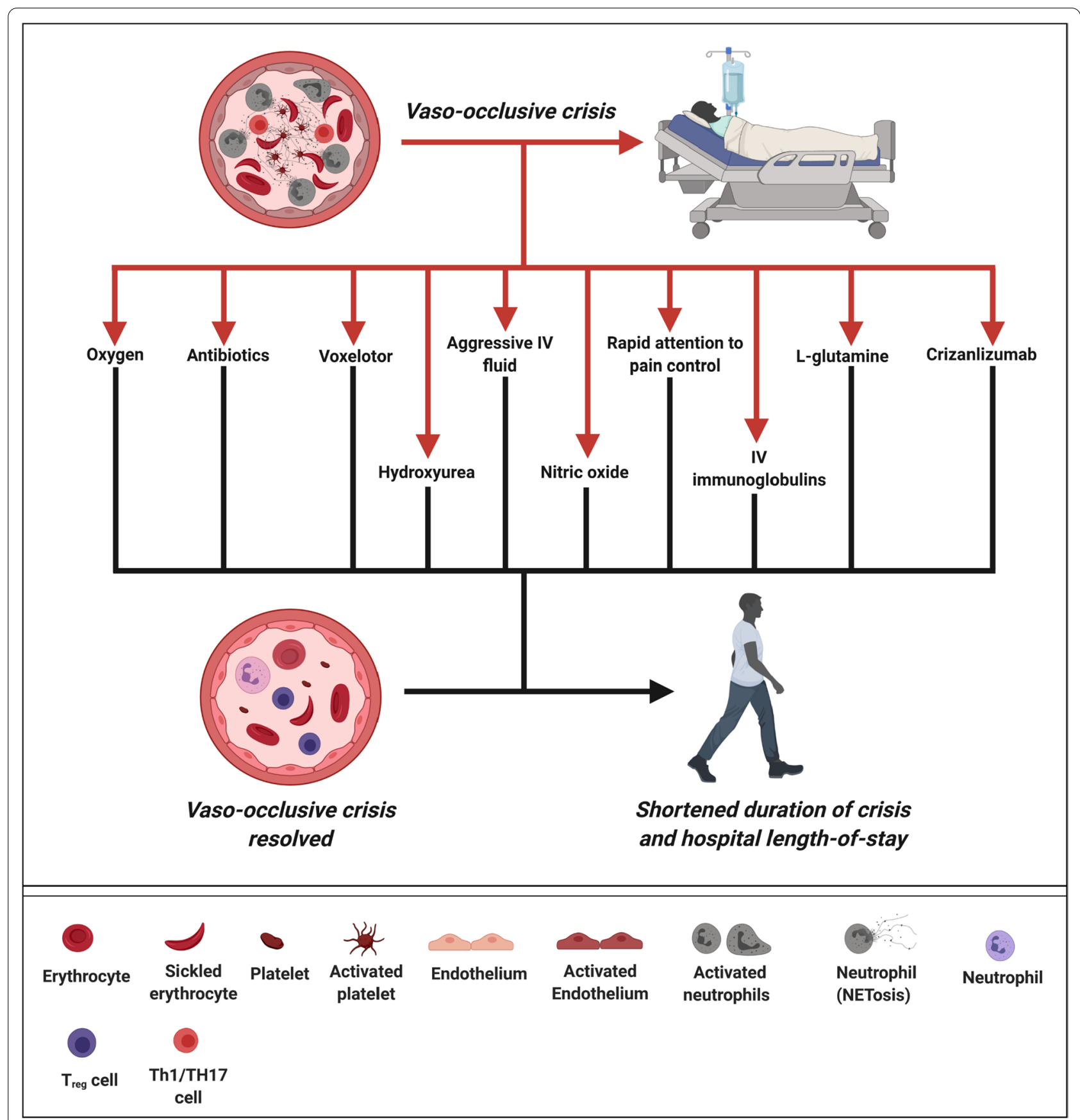

Fig. 3 A proposed multipronged approach to treating VOC. Instead of just using intravenous fluid, oxygen, and pain management and wait for the VOC process to resolve spontaneously, a more proactive approach is proposed using a combination of the listed agents to target as many of the downstream processes as possible. Acute use of antisickling agents such as voxelotor may protect the un-involved erythrocytes from sickling induced by the many downstream events of VOC. On the other hand, approaches that target the downstream events will more likely be successful if used in combination to overcome as many of the downstream pathways as possible 


\section{Abbreviations}

BACH: BTB and CNC homologue; CANs: Circulating aged neutrophils; CD: Cluster of differentiation; DNA: Deoxyribonucleic acid; ED: Emergency department; FITC: Fluorescein isothiocyanate; $\mathrm{Hb}$ : Hemoglobin; HbF: Fetal hemoglobin; HbS: Sickle hemoglobin; ICAM: Intercellular adhesion molecules; iFABP: Intestinal fatty acid binding proteins; IL: Interleukin; iNKT: Invariant natural killer T; IVlg: Intravenous immunoglobulins; LOS: Length-of-stay; LPS: Lipopolysaccharides; Myd: Myeloid differentiation; NAC: N-Acetylcysteine; NETosis: Neutrophil extracellular traps; NSAID: Non-steroidal anti-inflammatory drug; NO: Nitric oxide; ROS: Radical oxygen species; SCD: Sickle cell disease; STAT: Signal transducer and activator of transcription; sVOC: Secondary vaso-occlusive crisis; TLR: Toll-like receptor; TNF: Tumor necrosis factor; VOC: Vaso-occlusive crisis.

\section{Acknowledgements}

Figures are created with BioRender.com.

\section{Authors' contributions}

TJ, MP, EC, and GM carried out the literature search and wrote the initial drafts of the manuscript. DD coordinated, supervised and guided writing of the draft and design of the figures. SHL conceived the idea and was responsible for the overall writing and final draft of the manuscript. All authors read and approved the final manuscript.

\section{Funding}

None.

\section{Availability of data and materials}

N/A

\section{Declarations}

Ethics approval and consent to participate N/A.

\section{Consent for publication}

N/A.

\section{Competing interests}

All authors declare no competing interests.

Received: 27 August 2021 Accepted: 8 September 2021

Published online: 20 September 2021

\section{References}

1. Centers for Disease Control and Prevention. 2020. Data and statistics on sickle cell disease. www.cdc.gov/ncbddd/sicklecell/data.html.

2. Steiner CA, Miller JL. Sickle Cell Disease Patients in U.S. Hospitals, 2004: Statistical Brief \#21. Healthcare Cost and Utilization Project (HCUP) Statistical Briefs. Rockville (MD); 2006.

3. Brousseau DC, Owens PL, Mosso AL, Panepinto JA, Steiner CA. Acute care utilization and rehospitalizations for sickle cell disease. JAMA 2010;303:1288-94.

4. Brousseau DC, Steiner CA, Owens P, Mosso A, Panepinto JA. Emergency department treat-and-release visits for sickle cell disease: a sign of acute events to come. Blood. 2011;118:169.

5. Ballas SK, Smith ED. Red blood cell changes during the evolution of the sickle cell painful crisis. Blood. 1992;79:2154-63.

6. Ballas SK. The sickle cell painful crisis in adults: phases and objective signs. Hemoglobin. 1995:19:323-33.

7. Dutta D, Aujla A, Knoll BM, Lim SH. Intestinal pathophysiological and microbial changes in sickle cell disease: potential targets for therapeutic intervention. Br J Haematol. 2020;188:488-93.

8. Fingar KR, Owens PL, Reid LD, Mistry KB, and Barrett ML. Characteristics of inpatient hospital stays involving sickle cell disease, 2000-2016. Healthcare Cost and Utilization Project (HCUP) Statistical Briefs [Internet]. Rockville (MD): Agency for Healthcare Research and Quality (US); 2006 Feb. 2019 Sep 3
9. Jang T, Mo G, Stewart C, Egini O, Dutta D, Muthu J, Lim SH. Antibiotic use in adults during sickle cell vaso-occlusive crisis: is it time for a controlled trial? Br J Haematol. 2021:193:1281-3.

10. Anyaegbu CC, Okpala IE, Akren'Ova YA, Salimonu LS. Peripheral blood neutrophil count and candidacidal activity correlate with the clinical severity of sickle cell anaemia (SCA). Eur J Haematol. 1998;60:267-8.

11. Dutta $D$, Methe $B$, Amar $S$, Morris $A$, Lim SH. Intestinal injury and gut permeability in sickle cell disease. J Transl Med. 2019;17:183.

12. Lard LR, Mul FP, de Haas M, Roos D, Duits AJ. Neutrophil activation in sickle cell disease. J Leukoc Biol. 1999;66:411-5.

13. Lum AF, Wun T, Staunton D, Simon SI. Inflammatory potential of neutrophils detected in sickle cell disease. Am J Hematol. 2004;76:126-33.

14. Belcher JD, Marker PH, Weber JP, Hebbel RP, Vercellotti GM. Activated monocytes in sickle cell disease: potential role in the activation of vascular endothelium and vaso-occlusion. Blood. 2000;96:2451-9.

15. Sparkenbaugh E, Pawlinski R. Interplay between coagulation and vascular inflammation in sickle cell disease. Br J Haematol. 2013;162:3-14.

16. Browne P, Shalev O, Hebbel RP. The molecular pathobiology of cell membrane iron: the sickle red cell as a model. Free Radic Biol Med. 1998;24:1040-8.

17. Turhan A, Weiss LA, Mohandas N, Coller BS, Frenette PS. Primary role for adherent leukocytes in sickle cell vascular occlusion: a new paradigm. Proc Natl Acad Sci USA. 2002;99:3047-51.

18. Merle NS, Grunenwald A, Rajaratnam H, Gnemmi V, Frimat M, Figueres ML, Knockaert S, Bouzekri S, Charue D, Noe R, Robe-Rybkine T, Le-Hoang M, Brinkman N, Gentinetta T, Edler M, Petrillo S, Tolosano E, Miescher S, Le Jeune S, Houillier P, Chauvet S, Rabant M, Dimitrov JD, Fremeaux-Bacchi V, Blanc-Brude OP, Roumenina LT. Intravascular hemolysis activates complement via cell-free heme and heme-loaded microvesicles. JCI Insight. 2018;3:e96910.

19. Pradhan P, Vijayan $V$, Gueler F, Immenschuh S. Interplay of heme with macrophages in homeostasis and inflammation. Int J Mol Sci. 2020;21:740.

20. Chen G, Zhang D, Fuchs TA, Manwani D, Wagner DD, Frenette PS. Hemeinduced neutrophil extracellular traps contribute to the pathogenesis of sickle cell disease. Blood. 2014;123:3818-27.

21. Schaer DJ, Buehler PW. Cell-free hemoglobin and its scavenger proteins: new disease models leading the way to targeted therapies. Cold Spring Harb Perspect Med. 2013;3:013433.

22. Nagano S, Otsuka T, Niiro H, Yamaoka K, Arinobu Y, Ogami E, Akahoshi M, Inoue Y, Miyake K, Nakashima H, Niho Y, Harada M. Molecular mechanisms of lipopolysaccharide-induced cyclooxygenase-2 expression in human neutrophils: involvement of the mitogen-activated protein kinase pathway and regulation by anti-inflammatory cytokines. Intern Immunol. 2002;14:733-40.

23. Bryant CE, Spring DR, Gangloff M, Gay NJ. The molecular basis of the host response to lipopolysaccharide. Nat Rev Microbiol. 2010;8:8-14.

24. Zhang D, Chen G, Manwani D, Mortha A, Xu C, Faith JJ, Burk RD, Kunisaki Y, Jang JE, Scheiermann C, Merad M, Frenette PS. Neutrophil ageing is regulated by the microbiome. Nature. 2015;525:528-32.

25. Niihara Y, Miller ST, Kanter J, Lanzkron S, Smith WR, Hsu LL, Gordeuk VR, Viswanathan K, Sarnaik S, Osunkwo I, Guillaume E, Sadanandan S, Sieger L, Lasky JL, Panosyan EH, Blake OA, New TN, Bellevue R, Tran LT, Razon RL, Stark CW, Neumayr LD, Vichinsky EP. Investigators of the phase 3 trial of L-glutamine in sickle cell disease. A phase 3 trial of L-glutamine in sickle cell disease. N Engl J Med. 2018;379:226-35.

26. Lim SH, Morris A, Li K, Fitch AC, Fast L, Goldberg L, Quesenberry M, Sprinz $P$, Methé $B$. Intestinal microbiome analysis revealed dysbiosis in sickle cell disease. Am J Hematol. 2018;93:E91-3.

27. Lim SH, Dutta D, Moore J. Rifaximin in sickle cell disease. Am J Hematol. 2019;94:E325-8.

28. Dutta D, Li K, Methe B, Lim SH. Rifaximin on intestinally-related pathologic changes in sickle cell disease. Am J Hematol. 2020;95:E83-6.

29. Granger DN, Kvietys PR. Reperfusion injury and reactive oxygen species: the evolution of a concept. Redox Biol. 2015;6:524-51.

30. Hidalgo A, Chang J, Jang JE, Peired AJ, Chiang EY, Frenette PS. Heterotypic interactions enabled by polarized neutrophil microdomains mediate thromboinflammatory injury. Nat Med. 2009;15:384-91.

31. Wallace KL, Marshall MA, Ramos SI, Lannigan JA, Field JJ, Strieter RM, Linden J. NKT cells mediate pulmonary inflammation and dysfunction in 
murine sickle cell disease through production of IFN-gamma and CXCR3 chemokines. Blood. 2009;1 14:667-76.

32. Sparkenbaugh E, Pawlinski R. Prothrombotic aspects of sickle cell disease. J Thromb Haemost. 2017;15:1307-16.

33. Mitchell MJ, Kawchak DA, Stark L, Zemel BS, Ohene-Frempong K, Stallings VA. Brief report: parent perspectives of nutritional status and mealtime behaviors in children with sickle cell disease. J Pediatr Psychol. 2004;29:315-20

34. Jang T, Mo G, Stewart C, Khoury L, Ferguson N, Egini O, Muthu J, Dutta D, Salifu M, Lim SH. Obesity and diabetes mellitus in patients with sickle cell disease. Ann Hematol. 2021. https://doi.org/10.1007/ s00277-021-04578-w.

35. Liu SC, Zhai S, Palek J. Detection of hemin release during hemoglobin S denaturation. Blood. 1988;71:1755-8.

36. Carvalho MOS, Rocha LC, Reis JHO, de Araújo Santos T, do Nascimento VML, Carvalho MB, Luz NF, de Matos Borges V, Goncalves MS. Heme concentration as a biomarker of sickle cell disease severity: its role in steady-state and in crisis patients. Blood. 2015;126:975.

37. Silva M, Videira PA, Sackstein R. E-Selectin ligands in the human mononuclear phagocyte system: implications for infection, inflammation, and immunotherapy. Front Immunol. 2017;8:1878.

38. Schimmel M, Nur E, Biemond BJ, van Mierlo GJ, Solati S, Brandjes DP, Otten HM, Schnog JJ, Zeerleder S. Nucleosomes and neutrophil activation in sickle cell disease painful crisis. Haematologica. 2013;98:1797-803.

39. Kruger P, Saffarzadeh M, Weber ANR, Rieber N, Radsak M, von Bernuth H, Benarafa C, Roos D, Skokowa J, Hartl D. Neutrophils: between host defence, immune modulation, and tissue injury. PLoS Pathog. 2015;11:e1004651.

40. Fuchs TA, Brill A, Duerschmied D, Schatzberg D, Monestier M, Myers DD Jr, Wrobleski SK, Wakefield TW, Hartwig JH, Wagner DD. Extracellular DNA traps promote thrombosis. Proc Natl Acad Sci USA. 2010;107:15880-5.

41. Huang $Y M$, Wang H, Wang C, Chen M, Zhao MH. Promotion of hypercoagulability in antineutrophil cytoplasmic antibody-associated vasculitis by $\mathrm{C} 5 \mathrm{a}$-induced tissue factor-expressing microparticles and neutrophil extracellular traps. Arthritis Rheumatol. 2015;67:2780-90.

42. Cameron SJ, Mix DS, Ture SK, Schmidt RA, Mohan A, Pariser D, Stoner MC, Shah P, Chen L, Zhang H, Field DJ, Modjeski KL, Toth S, Morrell CN. Hypoxia and ischemia promote a maladaptive platelet phenotype. Arterioscler Thromb Vasc Biol. 2018;38:1594-606.

43. Riboldi E, Porta C, Morlacchi S, Viola A, Mantovani A, Sica A. Hypoxiamediated regulation of macrophage functions in pathophysiology. Int Immunol. 2013;25:67-75.

44. Hoenderdos K, Lodge KM, Hirst RA, Chen C, Palazzo SGC, Emerenciana A, Summers C, Angyal A, Porter L, Juss JK, O'Callaghan C, Chilvers ER, Condliffe AM. Hypoxia upregulates neutrophil degranulation and potential for tissue injury. Thorax. 2016;71:1030-8.

45. Zennadi R, Moeller BJ, Whalen EJ, Batchvarova M, Xu K, Shan S, Delahunty M, Dewhirst MW, Telen MJ. Epinephrine-induced activation of LW-mediated sickle cell adhesion and vaso-occlusion in vivo. Blood. 2007;110:2708-17.

46. Porter LS, Gil KM, Carson JW, Anthony KK, Ready J. The role of stress and mood in sickle cell disease pain: an analysis of daily diary data. J Health Psychol. 2000:5:53-63.

47. Xu C, Lee SK, Zhang D, Frenette PS. The gut microbiome regulates psychological-stress-induced inflammation. Immunity. 2020;53:417-28.

48. Charache S, Barton FB, Moore RD, Terrin ML, Steinberg MH, Dover GJ, Ballas SK, McMahon RP, Castro O, Orringer EP. Hydroxyurea and sickle cell anemia Clinical utility of a myelosuppressive "switching" agent. The Multicenter Study of Hydroxyurea in Sickle Cell Anemia. Medicine (Baltimore). 1996;75:300-26

49. Saunthararajah $Y$, Hillery CA, Lavelle D, Molokie R, Dorn L, Bressler L, Gavazova S, Chen Y-H, Hoffman R, DeSimone J. Effects of 5-aza2-deoxycytidine on fetal hemoglobin levels, red cell adhesion, and hematopoietic differentiation in patients with sickle cell disease. Blood. 2003;102:3865-70.

50. McArthur JG, Svenstrup N, Chen C, Fricot A, Carvalho C, Nguyen J, Nguyen P, Parachikova A, Abdulla F, Vercellotti GM, Hermine O, Edwards D, Ribeil JA, Belcher JD, Maciel TT. A novel, highly potent and selective phosphodiesterase-9 inhibitor for the treatment of sickle cell disease. Haematologica. 2020;105:623-31.
51. Vichinsky E, Hoppe CC, Ataga KI, Ware RE, Nduba V, El-Beshlawy A, Hassab $\mathrm{H}$, Achebe MM, Alkindi S, Brown RC. A phase 3 randomized trial of voxelotor in sickle cell disease. N Engl J Med. 2019;381:509-19.

52. Hutchaleelaha A, Patel M, Washington C, Siu V, Allen E, Oksenberg D, Gretler DD, Mant T, Lehrer-Graiwer J. Pharmacokinetics and pharmacodynamics of voxelotor (GBT440) in healthy adults and patients with sickle cell disease. Br J Clin Pharmacol. 2019:85:1290-302.

53. Nur E, Brandjes DP, Teerlink T, Otten HM, Oude Elferink RP, Muskiet F, Evers LM, ten Cate H, Biemond BJ, Duits AJ, Schnog JJ. N-acetylcysteine reduces oxidative stress in sickle cell patients. Ann Hematol. 2012;91:1097-105.

54. Sins JWR, Fijnvandraat K, Rijneveld AW, Boom MB, Kerkhoffs JH, van Meurs AH, de Groot MR, Heijboer H, Dresse MF, Lê PQ, Hermans P, Vanderfaeillie A, Van Den Neste EW, Benghiat FS, Kesse-Adu R, Delannoy A, Efira A, Azerad MA, de Borgie CA, Biemond BJ. Effect of $\mathrm{N}$-acetylcysteine on pain in daily life in patients with sickle cell disease: a randomised clinical trial. Br J Haematol. 2018;182:444-8.

55. Holdiness MR. Clinical pharmacokinetics of $N$-acetylcysteine. Clin Pharmacokinet. 1991;20:123-34

56. Kharalkar SS, Joshi GS, Musayev FN, Fornabaio M, Abraham DJ, Safo MK. Identification of novel allosteric regulators of human-erythrocyte pyruvate kinase. Chem Biodivers. 2007;4:2603-17.

57. Rab MAE, Bos J, van Oirschot BA, van Straaten S, Kosinski PA, Chubukov V, Kim H, Mangus H, Schutgens REG, Pasterkamp G, Dang L, Kung C, van Beers EJ, van Wijk R. Decreased activity and stability of pyruvate kinase in sickle cell disease: a novel target for mitapivat therapy. Blood. 2021;137:2997-3001.

58. Centers for Disease Control and Prevention (CDC). Sickle cell data collection data brief: Hydroxyurea use among Medicaid beneficiaries with sickle cell disease in California and Georgia, 2006-2016. November 13, 2019; https://www.cdc.gov/ncbddd/hemoglobinopathies/scdc-hydru xyurea-data-brief.html.

59. Penkert RR, Hurwitz JL, Thomas P, Rosch J, Dowdy J, Sun Y, Tang L, Hankins JS. Inflammatory molecule reduction with hydroxyurea therapy in children with sickle cell anemia. Haematologica. 2018;103:e50-4.

60. Lanaro C, Franco-Penteado CF, Albuqueque DM, Saad ST, Conran N, Costa FF. Altered levels of cytokines and inflammatory mediators in plasma and leukocytes of sickle cell anemia patients and effects of hydroxyurea therapy. J Leukoc Biol. 2009:85:235-42.

61. Beiter JL Jr, Simon HK, Chambliss CR, Adamkiewicz T, Sullivan K. Intravenous ketorolac in the emergency department management of sickle cell pain and predictors of its effectiveness. Arch Pediatr Adolesc Med. 2001;155:496-500.

62. Griffin TC, MCIntire D, Buchanan GR. High-dose intravenous methylprednisolone therapy for pain in children and adolescents with sickle cell disease. N Engl J Med. 1994;330:733-7.

63. Ataga KI, Kutlar A, Kanter J, Liles D, Cancado R, Friedrisch J, Guthrie TH, Knight-Madden J, Alvarez OA, Gordeuk VR. Crizanlizumab for the prevention of pain crises in sickle cell disease. N Engl J Med. 2017;376:429-39.

64. Telen MJ, Wun T, McCavit TL, De Castro LM, Krishnamurti L, Lanzkron S, Hsu LL, Smith WR, Rhee S, Magnani JL, Thackray H. Randomized phase 2 study of GMI-1070 in SCD: reduction in time to resolution of vaso-occlusive events and decreased opioid use. Blood. 2015;125:2656-64.

65. Field JJ, Majerus E, Gordeuk VR, Gowhari M, Hoppe C, Heeney MM, Achebe M, George A, Chu H, Sheehan B, Puligandla M, Neuberg D, Lin G, Linden J, Nathan DG. Randomized phase 2 trial of regadenoson for treatment of acute vaso-occlusive crises in sickle cell disease. Blood Adv. 2017:1:1645-9.

66. Turhan A, Jenab P, Bruhns P, Ravetch JV, Coller BS, Frenette PS. Intravenous immune globulin prevents venular vaso-occlusion in sickle cell mice by inhibiting leukocyte adhesion and the interactions between sickle erythrocytes and adherent leukocytes. Blood. 2004;103:2397-400.

67. Chang J, Shi PA, Chiang EY, Frenette PS. Intravenous immunoglobulins reverse acute vaso-occlusive crises in sickle cell mice through rapid inhibition of neutrophil adhesion. Blood. 2008;111:915-23.

68. Manwani D, Xu C, Lee SK, Amatuni G, Cohen HW, Carullo V, Morrone K, Davila J, Shi PA, Ireland K, Keenan J, Frenette PS. Randomized phase 2 trial of Intravenous Gamma Globulin (IVIG) for the treatment of acute vasoocclusive crisis in patients with sickle cell disease: lessons learned from the midpoint analysis. Complement Ther Med. 2020;52:102481.

69. Wang B, Wu G, Zhou Z, Dai Z, Sun Y, Ji Y, Li W, Wang W, Liu C, Han F, Wu Z. Glutamine and intestinal barrier function. Amino Acids. 2015;47:2143-54. 
70. De Castro LM, Zennadi R, Jonassaint JC, Batchvarova M, Telen MJ. Effect of propranolol as antiadhesive therapy in sickle cell disease. Clin Transl Sci. 2012;5:437-44.

71. Payne J, Aban I, Hilliard LM, Madison J, Bemrich-Stolz C, Howard TH, Brandow A, Waite $E$, Lebensburger JD. Impact of early analgesia on hospitalization outcomes for sickle cell pain crisis. Pediatr Blood Cancer. 2018;65:e27420.

72. Waugh WH, Daeschner CW 3rd, Files BA, McConnell ME, Strandjord SE. Oral citrulline as arginine precursor may be beneficial in sickle cell disease: early phase two results. J Natl Med Assoc. 2001;93:363-71.

73. Jaja SI, Ogungbemi SO, Kehinde MO, Anigbogu CN. Supplementation with I-arginine stabilizes plasma arginine and nitric oxide metabolites, suppresses elevated liver enzymes and peroxidation in sickle cell anaemia. Pathophysiology. 2016;23:81-5.

74. Gladwin MT, Kato GJ, Weiner D, Onyekwere OC, Dampier C, Hsu L, Hagar RW, Howard T, Nuss R, Okam MM, Tremonti CK, Berman B, Villella A, Krishnamurti L, Lanzkron S, Castro O, Gordeuk VR, Coles WA, Peters-Lawrence M, Nichols J, Hall MK, Hildesheim M, Blackwelder WC, Baldassarre J, Casella JF. Nitric oxide for inhalation in the acute treatment of sickle cell pain crisis: a randomized controlled trial. JAMA. 2011;305:893-902.

75. Aboursheid T, Albaroudi O, Alahdab F. Inhaled nitric oxide for treating pain crises in people with sickle cell disease. Cochrane Database Syst Rev. 2019;11(10):CD011808.

76. Gaartman AE, Sayedi AK, Gerritsma JJ, de BackTR, van Tuijn CF, Tang MW, Heijboer H, de Heer K, Biemond BJ, Nur E. Fluid overload due to intravenous fluid therapy for vaso-occlusive crisis in sickle cell disease: incidence and risk factors. Br J Haematol. 2021. https://doi.org/10.1111/bjh.17696.
77. Okpala I. The management of crisis in sickle cell disease. Eur J Haematol. 1998;60:1-6.

78. Wun T, Soulieres D, Frelinger AL, Krishnamurti L, Novelli EM, Kutlar A, Ataga KI, Knupp CL, McMahon LE, Strouse JJ, Zhou C, Heath LE, Nwachuku CE, Jakubowski JA, Riesmeyer JS, Winters KJ. A double-blind, randomized, multicenter phase 2 study of prasugrel versus placebo in adult patients with sickle cell disease. J Hematol Oncol. 2013;6:17.

79. Lee SP, Ataga KI, Zayed M, Manganello JM, Orringer EP, Phillips DR, Parise LV. Phase I study of eptifibatide in patients with sickle cell anaemia. Br J Haematol. 2007;139:612-20.

80. Qari MH, Aljaouni SK, Alardawi MS, Fatani H, Alsayes FM, Zografos P, Alsaigh M, Alalfi A, Alamin M, Gadi A, Mousa SA. Reduction of painful vaso-occlusive crisis of sickle cell anaemia by tinzaparin in a double-blind randomized trial. Thromb Haemost. 2007;98:392-6.

81. Biemond BJ, Tombak A, Kilinc Y, Al-Khabori M, Abboud M, Nafea M, Inati A Wali Y, Kristensen J, Kowalski J, Donnelly E, Ohd J. Sevuparin for the treatment of acute pain crisis in patients with sickle cell disease: a multicentre, randomised, double-blind, placebo-controlled, phase 2 trial. Lancet Haematol. 2021;8:e334-43.

\section{Publisher's Note}

Springer Nature remains neutral with regard to jurisdictional claims in published maps and institutional affiliations.
Ready to submit your research? Choose BMC and benefit from:

- fast, convenient online submission

- thorough peer review by experienced researchers in your field

- rapid publication on acceptance

- support for research data, including large and complex data types

- gold Open Access which fosters wider collaboration and increased citations

- maximum visibility for your research: over $100 \mathrm{M}$ website views per year

At BMC, research is always in progress.

Learn more biomedcentral.com/submissions 